\title{
Professional values of baccalaureate nursing students in Jamaica
}

\author{
Sandra L. Chisholm-Ford * Pauline Anderson-Johnson, Mauvette J. Waite, Sheryl N. Garriques-Lloyd \\ School of Nursing, University of the West Indies, Mona, Jamaica
}

Received: May 31, 2016

Accepted: September 11, $2016 \quad$ Online Published: October 30, 2016

DOI: $10.5430 /$ jnep.v7n3p47

URL: http://dx.doi.org/10.5430/jnep.v7n3p47

\begin{abstract}
Background/Objective: Print, broadcast and social media in Jamaica have highlighted numerous negative attitudes and behaviours of practicing nurses, while anecdotal reports indicate that attitudes and values displayed by a significant number of nursing students have been less than desirable. Professional values of nursing students are engendered during interactions and associations with nursing professionals; therefore, this study aims to determine professional values of nursing students as well as associations between age and professional values.

Methods: A descriptive study was conducted among 102 randomly selected third year students from a school of nursing. Data were collected using a modified version of the 5-dimension (Caring, Trust, Professionalism, Activism and Justice) 26-item Nurses Professional Values Scale-Revised (NPVS-R) Tool. This tool has a scale ranging from 1-5 with 1 representing "not important" and 5 representing "most important". Data were analyzed using the Statistical Package for the Social Sciences (SPSS) version 17.0. Descriptive statistics including mean and standard deviation were used to summarize the data.

Results: The response rate was $98 \%$ and all respondents were females aged 19-39 years. Overall mean scores for the tool were high (4.40 \pm 0.51$)$. Trust scored highest (4.62 \pm 0.41$)$ and Caring lowest ( $4.20 \pm 0.52)$. Also, of the 26 items, "honest and accurate documentation" scored highest $(4.88 \pm 0.41)$ and the item "willing to take risks to protect clients and colleagues", scored lowest ( $3.15 \pm 1.08)$. The oldest respondents (25-39 years) scored highest on items related to Professionalism but lowest on Caring, Activism and Justice; while the youngest respondents (19-21 years) scored lowest on Professionalism.

Conclusions: Caring and Professionalism received the lowest scores. Notably, the value of Professionalism increased with age while the Caring value decreased. In an effort to improve all professional values among future nurses, a multi-dimensional approached should be undertaken to maintain the standards of nursing care and to improve public perception.
\end{abstract}

Key Words: Caring, Professionalism, Activism, Trust, Justice

\section{INTRODUCTION}

Nursing professionals are continuously being evaluated by the public for their selflessness, personal appearance, behaviours and verbal expressions. Print, broadcast and social media in Jamaica have placed intense scrutiny on nurses Numerous negative attitudes and behaviours were highlighted in several instances where unprofessional values were dis- played. ${ }^{[1,2]}$ Values are attitudes, beliefs and priorities that guide behaviour ${ }^{[3]}$ therefore, professional values form the foundation for nursing practice and include attitude, appearance and willingness to help others. ${ }^{[4]}$ Although these media reports only point to unprofessional values among practicing nurses; anecdotal reports from both clinical and academic nursing leaders indicate that attitudes and values displayed

\footnotetext{
* Correspondence: Sandra L. Chisholm-Ford; Email: sandra.chisholmford02@uwimona.edu.jm; Address: School of Nursing, University of the West Indies, Mona, Jamaica.

Published by Sciedu Press 
by a significant number of nursing students (from different schools of nursing) have been increasingly unprofessional.

This perceived deterioration must be investigated scientifically and if left without intervention will further the damage to the already fragile professional image. Studies have been undertaken to evaluate varying student and professional groups in North America, the United Kingdom and the Middle East, however, there is no documented record of professional values of nurses or nursing students in Jamaica or the Caribbean. The International Council of Nurse (ICN) Code of Ethics was used as the theoretical base.

\subsection{Literature review}

Nursing values are the most important components necessary for the maintenance of high quality standards in the nursing profession. ${ }^{[5]}$ Values form a framework for addressing ethical concerns ${ }^{[6]}$ and are translated as personal principles or standards of behaviour displayed by an individual. ${ }^{[7,8]}$ Similarly, professional values are important concepts that integrate the students' critical thinking as well as the moral and ethical skills needed to deliver competent nursing care. ${ }^{[8]}$

Professional values are reflections of personal values ${ }^{[6]}$ and are acquired during socialization into nursing. Globally, professional values in nursing has been described using varying characteristics, which, when translated, are fundamentally the same. Nursing core values have been identified as honesty, pursuit of new knowledge, belief in human dignity, equality of all patients and the desire to prevent and alleviate suffering. ${ }^{[4,9]}$ Protection of patient's privacy, protection from harm, personal and professional responsibility as well as accountability also featured prominently. However, the ICN subsumed all these values into five main ones: caring, activism, professionalism, trust, and justice. ${ }^{[10]}$

Professional behaviour is guided by personal principles, beliefs, and values which are found in the nurse's professional codes of ethics. ${ }^{[10]}$ Although different dimensions have been implicated in the development of professional values among nursing students, ${ }^{[11]}$ values displayed are direct reflections of the values acquired during socialization into nursing.

\subsubsection{Culture}

Culture plays an important role in the development of professional values. It also influences the development and prioritization of these nursing professional values and despite nursing values being the same across all jurisdictions, priority values differ according to culture. ${ }^{[12]}$ Values studied in the Japanese and American cultures determined that despite having similar values in both cultures, each country had values that were unique to them. ${ }^{[6]}$ This was supported by another study that identified unique cultural indicators in the Japanese culture. ${ }^{[13]}$

\subsubsection{Membership in professional organization}

The development of professional values has also been linked to active membership in the professional organization. Professional membership increases nurses' awareness of current nursing issues and trends as well as allowing them the opportunity to determine their own direction in the profession. ${ }^{[14]}$ Priority values derived from professional membership are different from those learnt in the classroom ${ }^{[15]}$ and student nurses with membership in their professional organization displayed greater professional values than those who are nonmembers. ${ }^{[16]}$ A cross sectional qualitative study conducted in four different hospitals in Ethiopia, concluded that nurses who joined the professional organization, as well as older nurses had higher professional value scores. ${ }^{[1]}$ It was also determined that involvement in professional organizations improves nurses' perception of their own professionalism while contributing to the growth of the organization. ${ }^{[16,18]}$

\subsubsection{Nursing education}

Nursing values are learnt through formal and informal means. ${ }^{[19]}$ Nursing education influences the formation and development of professional values ${ }^{[20]}$ and identity ${ }^{[21]}$ provides different approaches to learning and developing these values. ${ }^{[11]}$ A longitudinal study evaluated 94 Taiwanese students using the Nurses Professional Values Scale-Revised (NPVS-R), ${ }^{[22]}$ and it was determined that nursing education not only improved academics but also built on fundamental professional values. ${ }^{[14]}$

\subsubsection{Mentorship}

Mentoring of nursing students is an important portal through which nursing values are transferred. It was found that values displayed by nursing students were developed during interactions with, and observations of the nurse educator. ${ }^{[19-21]}$ Faculty also has the responsibility for providing encouragement and educational support in order to promote the extraction of professional values from their clinical experiences. ${ }^{[16]}$ The implementation of clear codes of conduct resulted in improved professional development and noticeably higher professional values among nursing students. ${ }^{[23]}$

Nursing values influence nursing actions and serves as a guide when dealing with ethical issues. ${ }^{[6]}$ Professional values and their resultant behaviour are cause for concern, ${ }^{[3]}$ with most nurses displaying very little respect for nursing values. ${ }^{[24]}$ Similarly, anecdotal reports from both clinical and educational nursing leaders in Jamaica indicate that attitudes and conducts displayed by a significant number of nursing students from different schools of nursing have increasingly been unprofessional. ${ }^{[25,26]}$ 
Therefore, this study was undertaken to measure the professional values of nursing students in order to investigate the perception of low nursing professional values. It may be used to help strengthen existing school curricula and provide a base for assigning mentors. Additionally, it should aid in cementing the importance of active involvement of nursing students in their professional organization.

\section{METHODS AND PROCEDURES}

\subsection{Research design}

The study was conducted using a descriptive study design. This design was chosen as it is best able to observe and describe the features of nursing professional values. ${ }^{[27]}$

\subsection{Population and setting}

The study population consisted of 3rd year nursing students registered at the School of Nursing. This school is one of the largest Schools of Nursing in urban Jamaica. The school admits students from a wide cross section of communities within the island and several Caribbean countries. The 3rd year group was comprised of 140 students; all students registered were eligible for inclusion. This group was selected based on their level of academic and clinical preparation as well as personal interactions with nursing personnel.

\subsection{Sampling size and procedure}

No published studies were found that gave an estimate of the prevalence of professional values among nursing students; therefore, the $50 \%$ estimate was used. Calculations were further conducted with a margin of error of $5 \%$ and a confidence interval of $95 \%$ using the formula: $\left[Z^{2 *} p^{*}(1-p) / C^{2}\right.$.

With $\mathrm{Z}=$ the standard value (1.96), $\mathrm{P}=$ the estimated parameter of interest-expressed as a decimal. $\mathrm{C}=$ Confidence interval also expressed as a decimal. The sample size was determined to be 377. Adjustments based on the small population were done, resulting in a sample size of 104 .

Simple random sampling technique was used to select the 104 students. The class register was used as the sampling frame and student's names were numbered consecutively from 1 to 140. The Random Generator software was used to generate a list of random numbers $(\mathrm{N}=104)$ and the names for all the numbers produced were selected.

\subsection{Instrument}

Data were collected using a modified version of the NPVS$\mathrm{R}$ Tool. ${ }^{[28]}$ The NPVS-R is a 5-dimension (Caring, Trust, Professionalism, Activism and Justice), 26-item instrument designed to measure professional values among nurses. The Caring dimension is comprised of nine items; Professionalism contains four, Justice has three, while Activism and
Trust contained five items each. The NPVS-R is a Likert type tool. Degrees of importance were determined as 1: not important, 2: somewhat important, 3: important, 4: very important, 5: most important. Each item in the NPVS-R is a short descriptive phrase reflecting a specific code provision and its interpretive commentary.

Subsequently, the original tool was scrutinized by a team of nursing professionals in Jamaica who have previously conducted research on professionalism. It was also examined by a group of students of a similar cohort at another school of nursing. Several items were identified as not being clear enough or not being applicable to the Jamaican context. Hence, these items were reworded or substituted, with care taken to ensure that the integrity of the dimensions was maintained. This was to ensure that language and contexts used were culturally appropriate and relevant to the Jamaican context.

\subsection{Pretesting}

The modified tool was pre-tested among ten 3rd year nursing students at another School of Nursing in order to determine the clarity of the instructions and the applicability of the instrument to nursing students in Jamaica. This was also to determine the average time needed to complete the questionnaire. The data were analyzed using SPSS version 17.0 to evaluate its reliability, which identified a Cronbach alpha of 0.96 .

\subsection{Ethical considerations}

The authors of the tool were contacted and permission obtained for the tool to be modified and used. Approval was obtained from the Ethics Committee, and Heads of both schools of nursing to commence pretesting and collection of the data for the study. Completed questionnaires were stored in a sealed cupboard at the school of nursing and will be discarded after three years using the shredding technique.

\subsection{Data collection method}

Data were collected following ethical approval, also with permission from the Head of School. Once the sample was selected, permission was obtained from the lecturers. The study was introduced to prospective respondents during a scheduled break between classes and the purpose of the study was explained and information regarding the random selection of participants was outlined. A signed informed consent was obtained before packages containing a cover letter and questionnaire were distributed; these were collected over a two-week period. Questionnaires were self-administered, and all questionnaires and consent forms were collected by the researcher and placed in sealed envelopes upon collection. 
The approximate time for completion of each questionnaire was 10 minutes.

\subsection{Reliability and validity}

The NPVS-R has been widely used and has shown reliability tests of 0.81 to 0.94 in previous studies conducted in Iran. ${ }^{[5,28]}$ The modified tool was pretested among third year student nurses $(n=10)$ at a similar facility to determine the clarity of the instructions and the applicability of the instrument to students in the Jamaican cultural context. For this study a Cronbach alpha of 0.86 was obtained.

\subsection{Consent}

The nature and purpose of the study was clearly outlined to each participant, their right to confidentiality as well as how the data would be used and stored. Informed consent was obtained by participants providing their signature on a written document signifying their voluntary participation. Consent forms and completed questionnaires are being kept in a locked cupboard at the University for three years after which they will be disposed of using the shredding technique. Participation in the study was strictly voluntary, and participants reserved the right to refuse to participate, or withdraw from the study at anytime they wished. In order to maintain the anonymity and confidentiality of each participant personal identifiers were not used.

\subsection{Data analysis}

Data were analyzed using the Statistical Package for the Social Sciences (SPSS) version 17.0. Descriptive statistics such as mean and standard deviation were used to summarize the data. The independent $t$-tests and ANOVA were used to examine relationships among the categorical variables and the five dimensions of professionalism. The level of significance for these tests was set at .05 . For the purpose of analysis age was condensed into three main categories namely 19-21, 22-24 and 25-39 years.

\section{Results}

A total of 104 questionnaires were distributed of which 102 were returned, reflecting a response rate of $98 \%$. Although most of the participants responded to all items, three re- spondents failed to answer question 8 , one failed to answer questions 7 and 10 while 11 failed to identify their method of financial support. All respondents were female; with 93\% being single. Ages ranged from 19 to 39 years with a mean age of $22 \pm 3.03$ and a median age of 21 years. For advanced analysis only three age groups were used 19-21, 22-24 and 25-39 years. Most of the respondents (60.8\%) were in the 19-21 age group. The majority of students (73.62\%) reported that they were supported by parents. Other means of financial support were summer jobs, spouses and part-time jobs (see Table 1).

Table 1. Demographic characteristics of the sample

\begin{tabular}{llll}
\hline Items & & $\mathbf{n}$ & $\mathbf{\%}$ \\
\hline \multirow{4}{*}{ Age (years) } & $19-21$ & 62 & 60.8 \\
& $22-24$ & 33 & 32.4 \\
& $25-39$ & 7 & 6.9 \\
Marital status & Single & 95 & 93.1 \\
& Married & 1 & 1.0 \\
& Common Law & 6 & 5.9 \\
Financial & Parents & 67 & 65.7 \\
Support & Spouse & 7 & 6.9 \\
& Work Part time & 10 & 9.8 \\
& Summer & 7 & 6.9 \\
& Did not respond & 11 & 10.8 \\
\hline
\end{tabular}

\subsection{Students' professional values}

The NPVS-R scale is divided into five subscales or dimensions: Caring, Professionalism, Justice, Activism and Trust. The Caring dimension is comprised of nine items; Professionalism contains four, Justice has three, while Activism and Trust contained five items each. The overall distribution for the questionnaire and each of the five subscales were normal. An overall mean score of $4.40 \pm 0.51$ was obtained for the tool. Ranking of dimensions was done according to the mean scores obtained. Trust ranked the highest of the five dimensions (4.62 \pm 0.41$)$, while the Caring dimension ranked lowest $(4.20 \pm 0.52)$ (see Table 2). Table 2 also shows the percentage of respondents who answered "most important" on all items. Justice had the highest percentage of $31.4 \%$ followed by Trust with $30.4 \%$ and Caring had the least with $2 \%$.

Table 2. Ranking of dimensions according to mean \pm SD, with percentage response to "Most Important" on all items

\begin{tabular}{lllll}
\hline Dimension & Ranking & Mean \pm SD & $\begin{array}{l}\text { 95\% Confidence } \\
\text { Interval }\end{array}$ & $\begin{array}{l}\text { Percentage (\%) of respondents stating “Most } \\
\text { Important” (5) on all items }\end{array}$ \\
\hline Trust & 1 & $4.62 \pm 0.41$ & $4.54-4.69$ & 30.4 \\
Justice & 2 & $4.44 \pm 0.54$ & $4.33-4.55$ & 31.4 \\
Professionalism & 3 & $4.38 \pm 0.48$ & $4.29-4.48$ & 10.8 \\
Activism & 4 & $4.34 \pm 0.58$ & $4.22-4.45$ & 21.6 \\
Caring & 5 & $4.20 \pm 0.52$ & $4.09-4.30$ & 2.0 \\
\hline
\end{tabular}


All the items for each dimension were summed and a mean score of $4.40 \pm 0.51$ was obtained (see Table 3 ). Table 3 also shows that the highest scoring item in the Caring dimension was 'Listen attentively and patiently to clients' questions and concerns" with $70.6 \%$ of respondents indicating "most important", while "Willing to take risk to protect clients and colleagues" scored lowest and also had the smallest proportion of students indicating "most important" (10.8\%).

Table 3. Mean score (SD) and ranking of items in the caring dimension

\begin{tabular}{llll}
\hline Components of the professional scale & Rank & Mean \pm SD & $\begin{array}{l}\text { Percentage (\%) of respondents stating } \\
\text { “Most Important” (5) on all items }\end{array}$ \\
\hline Caring & & & \\
\hline Listen attentively and patiently to clients questions and concerns & 1 & $4.65 \pm 0.61$ & 70.6 \\
Provides care without prejudice to patients of varying lifestyles & 2 & $4.60 \pm 0.63$ & 67.6 \\
Follows institutional policies and protocols & 3 & $4.54 \pm 0.69$ & 64.7 \\
Answers questions in an honest and sensitive manner & 4 & $4.49 \pm 0.70$ & 59.8 \\
Answer client's questions honestly & 5 & $4.28 \pm 0.81$ & 49.0 \\
Sits with dying patient and ensure comfort in their final moments & 6 & $4.25 \pm 0.88$ & 50.0 \\
Confronts colleagues whose practice may negatively impact patient & 7 & $4.21 \pm 0.88$ & 44.1 \\
safety and report to the relevant authority & 8 & $3.62 \pm 1.16$ & 26.5 \\
Assist in an emergency when off duty & 9 & $3.15 \pm 1.08$ & 10.8 \\
Willing to take risk to protect clients and colleagues & & &
\end{tabular}

In the Professionalism dimension (see Table 4) most respondents $(90 \%)$ indicated that "Documentation of care is honest and accurate" was the highest scored item (90.8\%), mean- while "Displays moral courage in confronting issues contrary to own personal beliefs" scored lowest with $35.4 \%$.

Table 4. Mean score (SD) and ranking of items in the professionalism dimension

\begin{tabular}{llll}
\hline Professionalism & Rank & Mean \pm SD & $\begin{array}{l}\text { Percentage (\%) of respondents stating } \\
\text { “Most Important” (5) on all items }\end{array}$ \\
\hline $\begin{array}{l}\text { Documentation of care is honest and accurate } \\
\begin{array}{l}\text { Shows respect to colleagues, clients and their significant } \\
\text { others at all times }\end{array}\end{array}$ & 2 & $4.88 \pm 0.41$ & 90.2 \\
$\begin{array}{l}\text { Refuses to participate in care if ethically inappropriate } \\
\begin{array}{l}\text { Displays moral courage in confronting issues contrary to } \\
\text { own personal beliefs }\end{array}\end{array}$ & 3 & $4.67 \pm 0.57$ & 71.3 \\
\hline
\end{tabular}

The Trust dimension (see Table 5) saw the item "Protects the client's right to privacy and confidentiality" scoring highest at $81.4 \%$ and "Provides competent care that is culturally sensitive" $58.8 \%$ had the lowest score.
With only three items in the Justice dimension (see Table 6), the item scoring highest with $67.6 \%$ was "Provides nondiscriminatory nursing care" and "Provides equitable access to nursing services" reported the lowest score of $38.2 \%$.

Table 5. Mean score (SD) and ranking of items in the trust dimension

\begin{tabular}{llll}
\hline Trust & Rank & Mean \pm SD & $\begin{array}{l}\text { Percentage(\%) of respondents stating } \\
\text { “Most Important” (5) on all items }\end{array}$ \\
\hline Protects the client's right to privacy and confidentiality & 1 & $4.79 \pm 0.45$ & 81.4 \\
Plans care that is sensitive to individual client needs & 2 & $4.69 \pm 0.58$ & 74.5 \\
Advocates for the rights of patients & 3 & $4.60 \pm 0.75$ & 72.0 \\
Maintains correct procedures and protocols when no one is looking & 4 & $4.55 \pm 0.70$ & 66.7 \\
Provides competent care that is culturally sensitive & 5 & $4.47 \pm 0.70$ & 58.8 \\
\hline
\end{tabular}


Table 6. Mean score (SD) and ranking of items in the justice dimension

\begin{tabular}{llll}
\hline Justice & Rank & Mean \pm SD & $\begin{array}{l}\text { Percentage (\%) of respondents stating “Most } \\
\text { Important”(5) on all items }\end{array}$ \\
\hline Provides nondiscriminatory nursing care & 1 & $4.61 \pm 0.65$ & 67.6 \\
Protects health and safety of the public & 2 & $4.51 \pm 0.78$ & 66.7 \\
Provides equitable access to nursing services & 3 & $4.21 \pm 0.72$ & 38.2 \\
\hline
\end{tabular}

The highest scoring item in the Activism dimension (see Table 7) with $68.6 \%$ was "Utilizes nursing research findings to guide your practice in the clinical area" and "Participates in activities of the Student Nurses' Association" scored lowest with $32.4 \%$.

Table 7. Mean score (SD) and ranking of items in the activism dimension

\begin{tabular}{llll}
\hline Activism & Rank & Mean \pm SD & $\begin{array}{l}\text { Percentage (\%) of respondents stating } \\
\text { “Most Important” (5) on all items }\end{array}$ \\
\hline $\begin{array}{l}\text { Utilizes nursing research findings to guide your practice in the } \\
\text { clinical area }\end{array}$ & 1 & $4.59 \pm 0.67$ & 68.6 \\
$\begin{array}{l}\text { Reevaluates care in order to improve outcomes } \\
\begin{array}{l}\text { Assesses own practice and undertakes measures to improve } \\
\text { practice }\end{array}\end{array}$ & 2 & $4.55 \pm 0.59$ & 59.4 \\
$\begin{array}{l}\text { Recognizes role professional nursing association in shaping } \\
\text { health care policy }\end{array}$ & 4 & $4.48 \pm 0.70$ & 57.8 \\
\begin{tabular}{l} 
Participates in activities of the Student Nurses' Association \\
\hline
\end{tabular} & 5 & $3.72 \pm 1.21$ & 32.4 \\
\hline
\end{tabular}

\subsection{Associations between age and professional values}

Results showed that respondents in the oldest age group (2539) scored lowest on three dimensions: Caring, Justice and Activism, but scored highest in Professionalism (19.14 \pm 1.07) (see Table 8). It is also keen to note that respondents within this age group were the only ones to score maximum scores of $5.00 \pm 0.000$ on any item. Maximum scores were obtained on the following five items: "Willing to take risk to protect clients and colleagues", "Documentation of care is honest and accurate", "Displays moral courage in confronting issues contrary to own personal beliefs", "Maintains correct procedures and protocols when no one is looking" and "Protects the client's right to privacy and confidentiality." On the other hand, "Sits with dying patient and ensure
Overall, the highest scoring item was "documentation of care is honest and accurate" with a mean of $4.84 \pm 0.486$ and the item scoring lowest was "willing to take risk to protect clients and colleagues" with a mean of $3.15 \pm 1.053$. comfort in their final moments" obtained the least score with a mean score of $3.43 \pm 0.54$. Conversely, the 19-21 age group scored highest on three dimensions; Trust, Activism and Justice but scored lowest in Professionalism (17.25 \pm 1.90).

The highest scoring items "Documentation of care is honest and accurate" and "Protects the client's right to privacy and confidentiality" had the highest percentage of students identifying these items as most important, with $90.2 \%$ and $81.4 \%$ respectively. In contrast "Assist in an emergency when off duty" and "Willing to take risk to protect clients and colleagues" recorded the lowest percentage of students stating "most important", making them the lowest scoring items with $26.5 \%$ and $10.8 \%$ respectively.

Table 8. Mean scores of dimensions by age group

\begin{tabular}{llllllll}
\hline Dimensions & $\begin{array}{l}\text { 19- 21 yrs } \\
(\mathbf{n = ~ 6 2 )}\end{array}$ & $\begin{array}{l}\mathbf{2 2 - 2 4} \text { yrs } \\
(\mathbf{n}=\mathbf{3 3})\end{array}$ & $\begin{array}{l}\mathbf{2 5 - 3 9} \text { yrs } \\
(\mathbf{n}=\mathbf{7})\end{array}$ & $\begin{array}{l}\text { Total } \\
(\mathbf{n = 1 0 2})\end{array}$ & $\begin{array}{l}\text { Maximum } \\
\text { Score }\end{array}$ & $\begin{array}{l}\text { f-statistic } \\
\text { Value }\end{array}$ \\
\hline Caring & $37.77 \pm 4.89$ & $38.15 \pm 4.28$ & $36.14 \pm 2.88$ & $37.78 \pm 4.70$ & 45 & 0.744 & .59 \\
Justice & $13.55 \pm 1.47$ & $13.00 \pm 1.71$ & $12.86 \pm 2.11$ & $13.32 \pm 1.60$ & 15 & 1.592 & .21 \\
Professionalism & $17.25 \pm 1.90$ & $17.77 \pm 1.84$ & $19.14 \pm 1.07$ & $17.55 \pm 1.89$ & 20 & 3.679 & .03 \\
Trust & $23.21 \pm 2.02$ & $22.94 \pm 2.00$ & $23.14 \pm 2.19$ & $23.12 \pm 2.01$ & 25 & 0.190 & .83 \\
Activism & $22.13 \pm 2.02$ & $21.30 \pm 3.2$ & $20.00 \pm 2.1$ & $21.71 \pm 2.9$ & 25 & 2.268 & .11 \\
\hline
\end{tabular}




\section{Discussion AND CONCLUSION}

It was identified that despite low scores in some items, professional values were relatively high among the study participants. However, while younger students were more caring, older students were more professional. Notably, low scoring items were not significantly low. The high scores obtained for this study therefore means that the claim that nursing professional values among nursing students are low cannot be substantiated among this group. Essentially, this study demonstrated that the participants possess values that are synonymous with good nursing values. These findings are similar to a comparative study in the United States of America and Taiwan where culture was identified as a determinant in the value priority and some items were rated more highly than others. ${ }^{[12]}$ New graduates, graduate students as well as seasoned nursing professionals were not included in this study and may have been able to highlight a different perspective on media reports ${ }^{[1,2,25,26]}$ on the professional values of nurses in Jamaica.

The five items on which the 25-39 age group obtained highest scores may be equated with a high level of professional integrity. On the contrary, moral courage and commitment was low, as the item "willing to take risk to protect clients and colleagues" received the lowest percentage (10.8\%) of participants indicating "most important" on all questions. Only $26.6 \%$ of students indicated that it was most important to assist in an emergency when off duty. Despite nursing being a "helping profession", culture has been implicated in the students' attitudes towards offering help. ${ }^{[9]}$ The fear of litigation coupled with the lack of gratitude from the general public may be implicated in the unwillingness to offer help outside of duty hours.

On the other hand, the tedious documentation process after documentation ${ }^{[28,29]}$ coupled with the constant pressure to meet institutional and personal targets compounded with the increase in litigation against nursing personnel, ${ }^{[30]}$ have forced nursing students to focus more on documentation than actual care. It is evident that despite being faced with the tedious task of documentation a significant number of respondents still believed it was the most important item. "Documentation of care is honest and accurate" received the highest percentage (90.2\%) of students responding that it was most important. It was also concluded that nursing documentation is an essential component of quality nursing care. ${ }^{[31]}$

Underdeveloped critical thinking skills among nursing students are affecting their ability to make sound decisions during the care process. ${ }^{[32]}$ The need to facilitate critical thinking in nursing students cannot be over emphasized. ${ }^{[22]}$

Published by Sciedu Press
The fundamental professional responsibility of the nurses and nursing students alike is to ensure that clients are receiving the best possible care. This can only be achieved by treating all clients with dignity, respect, caring and compassion which is realized if the students possess the appropriate professional values; this can be obtained and developed during educational experiences. The positive effects of education on students' professional values were identified. ${ }^{[22]}$

There is a great degree of apathy towards the importance of the professional organization and the need for involvement with only $32 \%$ of respondents indicating that active involvement in the Student Nurses' Association was most important. Similar results were seen among different categories of student nurses in America. ${ }^{[33]}$ Eventually, this lack of interest will deprive students of educational, training and advocacy opportunities that are provided and facilitated by the professional organizations for practicing nurses and students alike. ${ }^{[34]}$

Trust and Caring were the highest and lowest valued dimensions respectively and the highest and lowest valued items were "documentation of care is honest and accurate" and "willing to take risks to protect clients and colleagues". The scores differed according to age group. The youngest age group recorded highest scores in the Trust, Activism and Justice dimensions, the median group had highest scores in Caring while the oldest group scored highest in Professionalism. However, these finding cannot be generalized to other school populations as only one year group in one school of nursing was used. Also, the use of self-administered questionnaires created the opportunity for more students to respond positively, as human nature leans toward responding in a way that may be viewed as favourable by others. ${ }^{[35]}$

It was interesting to note that students within the oldest age group were the only ones to record maximum mean scores of $5.00 \pm 0.000$ on any item. Similar finding was reported in another study. ${ }^{[36]}$ This may indicate that moral courage increases with age, where moral courage can be equated with personal courage. When nurses act without fear of job loss, ridicule or other types of humiliation moral courage can be credited. This professional maturity is linked to chronological maturity as these students have been exposed to the need to make independent judgments in their professional and personal lives. Older respondents with family and other personal responsibilities would be more mature hence their interpretation and responses to the questions within the professionalism dimension. In contrast, other studies saw professional values decreasing with age. ${ }^{[37,38]}$

The Caring dimension ranked lowest, astonishingly only $2 \%$ of respondents answered with "most important" on all 
questions. Opposite findings from another study saw Caring ranking highest. ${ }^{[22]}$ Students scored highest on items related to direct patient care comparable to another study. ${ }^{[33]}$ This low ranking of the Caring dimension in this study should not be equated with cruelty, general apathy, neglect or a lack of respect for the dying, but may be directly associated with the current nurse/patient ratio which is way below the required cadre. ${ }^{[39]}$ Sitting with a dying client may be construed as the least important task at a time when there are other pressing nursing activities to be carried out for live clients; this also has cultural implications. Despite, Caring having the lowest scores, the mean of $4.20 \pm 0.52$ can still be considered as high, and although achieving the lowest scores in this study the mean is higher than the mean of $3.62 \pm 0.65$ and its third place ranking in a similar study. ${ }^{[40]}$

Students in the oldest age group scored highest in Professionalism (19.14 \pm 1.07$)$. These findings were congruent with another study ${ }^{[12]}$ depicting the age of the student had some implications for the responses given. Older participants responded more positively to items of Trust while on the other hand, scoring lowest on four of five items in Activism. Low rankings in Activism were also found in other studies. ${ }^{[5,22,33]}$ The ranking of Trust and Caring as the highest and lowest respectively, is similar to another study ${ }^{[5]}$ where Trust ranked highest but Activism ranked lowest. The sample used, ${ }^{[5]}$ was two third female and one third male while this study population was entirely female. The total cohort had only two male students who did not return their questionnaires. Generally, the male to female ratio in schools of nursing is very wide with few males applying for admission to the programme. The lowest scored item in this study "sits with dying patient and ensure comfort in their final moments" belonged to the Caring dimension, on the contrary, in other studies the lowest scoring item was found in the Professionalism dimension. ${ }^{[5,33]}$ Low scores on this item may be related to cultural norms and the shortage of nursing personnel. ${ }^{[39]}$

\section{RECOMMENDATIONS}

Undoubtedly, the development of professional values is an important dimension to be considered in the education of nursing students. In an effort to improve all professional values among future nurses, a multi-dimensional approach should be undertaken to maintain the standards of nursing care and to improve public perception.

Consideration should be given to the inclusion of questions related to nursing professionalism at the intake interviews for prospective students. The students' personal values prior to entry into the school of nursing must also be determined.

An earlier introduction to professional nursing discourses should be considered, preferably during the first year of study. This should significantly improve the values of Caring and Activism where students scored lowest.

Assigning faculty advisors/mentors to each year group with the responsibility for establishing and maintaining students' contact with the professional organisation. Appropriate supervision, guidance and feedback on issues important to values could be beneficial.

The application of peer-mentorship (assigning a senior student to mentor a junior one), should also help improve the Activism and Professionalism values. Mentoring of students and proper role modeling should subsequently improve nursing practice and provide the work force with competent, values-oriented professionals.

Organizing projects to promote volunteerism and the development of altruism and morality should result in improved autonomy, critical thinking and decision making skills. Allowing students time within the Curriculum for involvement in activities within the professional organization should also be beneficial.

The nursing brand can also be improved by partnering with different media houses so that the positive issues and activities of the profession can be highlighted.

Professional values with the lowest scores require more keen focus, and improvement measures must be implemented in order to improve both nursing education and practice. The possible implementation of curriculum changes should be aimed at improving the dimensions with lower scores as well as educating students on the importance of membership and involvement in their professional organization.

Additionally, longitudinal studies on the current study group may be beneficial in identifying changes in professional values. This may be approached with the addition of a qualitative component or by using mixed methods. Further studies conducted among students from year one through to year four, and from different schools of nursing will be beneficial to nursing research in Jamaica and the Caribbean. Additionally, a qualitative component may be added in order to determine how other demographic and educational dimensions impact professional values. Students should also participate in and conduct research projects in order to develop and/or strengthen research skills.

The need for further qualitative research in order to; explore factors affecting the student nurses' response to the different items, determine their levels of confidence in making professionally moral and ethical decisions, and to determine the adequacy of the theoretical preparations received. 


\section{ACKNOWLEDGEMENTS}

We would like to thank the following persons for their significant contribution to the completion of this study: the Heads of the Schools of Nursing, for granting permission for the pretesting of the tool and the study to be conducted, the year three students of the school studied as well as those partici- pating in the pretesting of the tool. Lastly, Dr. Jascinth Lindo (Lecturer) and Rosain Stennett (Research Assistant) for the expert advice and support given.

\section{CONFlicts of InTEREST Disclosure}

The authors declare that there is no conflict of interest.

\section{REFERENCES}

[1] Cammock-Gayle M. Cold, callous care at University Hospital. The Gleaner. $2015 \mathrm{Jul}$ 4. Available from: http://jamaica-gleaner .com/article/commentary/20150704/melody-cammock-g ayle-cold-callous-care-university-hospital

[2] Hussey-White D. Mothers vow never to return to Jubilee. The Gleaner. 2014 Aug 3. Available from: http://jamaica-gleaner.com/p ower/10412

[3] Schwartz SH. An Overview of the Schwartz Theory of Basic Values. Online Readings in Psychology and Culture. 2012 Dec 1; 2(1). http://dx.doi.org/10.9707/2307-0919.1116

[4] Gokenbach V. Professionalism in Nursing: What Does It Really Mean? 2012 Oct 3. Available from: http://www.nursetogether.com/professionalism-i n-nursing-what-does-it-reall-mean

[5] Parvan K, Zamandazeh V, Alsadat Hosseini F. Assessment of Professional Values Among Iranian Nursing Students Studying in Universities With Different Norms of Educational Services. Thrita J Med Sci. 2012 Jun; 1(2): 37-43.

[6] Shahriari M, Mohammadi E, Abbaszadeh A, et al. Nursing ethical values and definitions: A literature review. Iran J Nurs Midwifery Res. 2013 Jan; 18(1): 1-8. PMid:23983720

[7] Iacobucci TA, Daly BJ, Lindell D, et al. Professional values, selfesteem, and ethical confidence of baccalaureate nursing students. Journal of Nursing Ethics. 2013; 20(4): 479-490. PMid:23166146 http://dx.doi.org/10.1177/0969733012458608

[8] Dehghani A, Mosalanejad L, Dehghan-Nayeri N. Factors affecting professional ethics in nursing practice in Iran: a qualitative study. BMC Med Ethics. 2015; 16: 61. http://doi.org/10.1186/s1 2910-015-0048-2

[9] Yarbrough S, Alfred D, Martin P. Research study: professional values and retention. Nurs Manage. 2008 Apr; 39(4): 10, 12 \& 14.

[10] International Council of Nurses. Available from: http://www.icn.ch/images/stories/documents/abou t/icncode_english.pdf

[11] Parandeh A, Khaghanizade M, Mohammadi E, et al. Factors influencing development of professional values among nursing students and instructors: a systematic review. Global Journal of Health Science. 2014 Nov; 7(2). PMid:25716397 http://dx. doi.org/10.5539 /gjhs.v7n2p284

[12] Alfred D, Yarbrough S, Martin P, et al. Comparison of professional values of Taiwanese and United States nursing students. J Nurs Eth. 2013 May; 20(8): 917-26. PMid:23702893 http://dx.doi.org $/ 10.1177 / 0969733013484486$

[13] Konishi E, Yahiro M, Nakajima N, et al. The Japanese value of harmony and nursing ethics. Nursing Ethics. 2009; 16(5): 625636. PMid:19671648 http://dx.doi .org/10.1177/096973300 9106654

Published by Sciedu Press
[14] UC Davis Medical Centre. Professional Organisations. Available from: http://www.ucdmc.ucdavis.edu/nurse/practicemo del/organizations.html

[15] Guerrieri R. Professional growth, learn, grow and bloom by joining a professional association. Nursing. 2010 May; 40(5): 4748. PMid:20386400 http://dx.doi.org/10.1097/01. NURSE. $0000371128.38511 .0 \mathrm{~d}$

[16] Wagner D. Promoting professionalism in RN-BSN education. Journal of Nursing Education and Practice. 2012; 3(5). http://dx. doi.o rg/10.5430/jnep.v3n5p9

[17] Fantahun A, Demessie A, Gebrekirstos K, et al. A cross sectional study on dimensions influencing professionalism in nursing among nurses in Mekelle Public Hospitals, North Ethiopia, 2012. BMC Nursing. 2014; 13: 10. PMid:24708544 http://dx.doi.org/10. 1186/1472-6955-13-10

[18] Catallo C, Spalding K, Roya Haghiri-Vijeh R. Nursing Professional Organizations: What Are They Doing to Engage Nurses in Health Policy? Sage Journals. 2014.

[19] Karimi Z, Ashktorab T, Mohammadi E, et al. Using the Hidden Curriculum to Teach Professionalism in Nursing Students. Iran Red Crescent Med J. 2014 Mar 5; 16(3): e15532. PMid:24829784 http://dx.doi.org/10.5812/ircmj. 15532

[20] Seylani K, Negarandeh R, Mohammadi E. Iranian undergraduate nursing student perceptions of informal learning: A qualitative research. Iran J Nurs Midwifery Res. 2012 Nov-Dec; 17(7): 493-500. PMid:23922595

[21] Zarshenas L, Farkhondeh Sharif F, Molazem Z, et al. Professional socialization in nursing: A qualitative content analysis. Iran J Nurs Midwifery Res. 2014 Jul; 19(4): 432-438. PMid:25183987

[22] Lin YH, Liching SW, Yarbrough S, et al. Changes in Taiwanese nursing student values during the educational experience. Nurs Ethics. 2010; 17(5): 646-54. PMid:20801966 http://dx.doi.org/10. $1177 / 0969733010373011$

[23] Anselmi K, Smith Glasgow ME, Gambescia SF. Using a nursing student conduct committee to foster professionalism among nursing students. Journal of Professional Nursing. 2014; 30(6): 481485. PMid:25455329 http://dx.doi.org/10.1016/j.profnur s.2014.04.002

[24] Mohsenpour M, Borhani F, Abbaszadeh A. Nursing students' understanding of dimensions influencing ethical sensitivity: A qualitative study. Iran J Nurs Midwifery Res. 2013; 18(4): 310-315. PMid:24403928

[25] Jamaica's Health Authority probes alleged misconduct at Linstead Hospital. The Gleaner. 2009 Jun 30. Available from: http://jama ica-gleaner.com/power/10412

[26] They took the hypocrites oath. The Observer. 2014 Aug 5. Available from: http://www.jamaicaobserver.com/news/_They _took_the_hypocrites_oath_1730334

[27] Polit D, Beck C. Nursing research: generating and assessing evidence for nursing practice. 9th Ed. China. JR Lippincott Company. 2012. 
[28] Weis D, Schank MJ. Development and psychometric evaluation of the nursing professional values scale - revised. J Nurs Meas. 2009; 17(3): 221-231. PMid:20069950 http://dx.doi.org/10.1891 /1061-3749.17.3.221

[29] Kahouei M, Baba Mohammadi H, Askari Majdabadi H, et al. Nurses' Perceptions of Usefulness of Nursing Information System: Module of Electronic Medical Record for Patient Care in Two University Hospitals of Iran. Materia Socio-Medica. 2014 Feb; 26(1): 30-34. http://dx.doi.org/10.5455/msm.2014.26.30-34

[30] Reising DL. Make your nursing care malpractice-proof. American Nurse Today. 2012; 7(1).

[31] Anderson L. The impact of documentation in nursing on quality care. 2012 Oct. Available from: http: //www. nursetogether.com/do cumentation-impact-on-quality-of-care-

[32] Yusuf FA. Developing Critical Thinking and Communication Skills in Students: Implications for Practice in Education. African Journals Online. 2012; 6(1): 311-324. http://dx.doi.org/10.4314/afr rev.v6i1.26

[33] Clarke DK. Professional Values: A study of education and experience in nursing students and nurses. ProQuest Dissertations and Theses. 2009.
[34] Matthews JH. Role of professional organizations in advocating for the nursing profession. OJIN. 2012 Jan.

[35] Berry CM, Carpenter NC, Barrat CL. Do Other-Reports of Counterproductive Work Behavior Provide an Incremental Contribution Over Self-Reports? A Meta-Analytic Comparison. J Appl Psychol. 2012 May; 97(3): 613-636. PMid:22201245 http://dx.doi.org/10. $1037 / \mathrm{a} 0026739$

[36] Van Schalkwyk T. International council of nurse. Ethics in nursing practice. A guide to ethical decision making. J Nurs Sci. 2012 Mar.

[37] Shahriari M, Baloochestani E. Applying professional values: the perspective of nurses of Isfahan hospitals. J Med Ethics Hist Med. 2014 Jun 6. PMid:25512822

[38] Parvan K, Hosseini F, Zamanzadeh V. Professional values from nursing students' perspective in Tabriz University of Medical Sciences: a pilot study. Iran J Nurs. 2012; 25(76): 28-41.

[39] Dunkley A. We are overworked. Jamaica Observer. 2011 Nov 11. Available from: http://www . jamaicaobserver.com/mobile/n ews/We-are-overworked--say-nurses_10134625

[40] Parvan K, Zamanzadeh V, Alsadat Hosseini F. Nursing students' perspectives on professional values in the universities of medical sciences in Iran International Research. J Appl Basic Sci. 2012 Dec; 3(6): 1183-1191 